\title{
Potentiation of EPN-Induced Inhibition of Liver Microsomal Carboxylesterase by Addition of Liver Cytosol from 6-Aminonicotinamide-Treated, Starved Rats
}

\author{
Seiyu SUGIYAMA, Tetsuo SATOH, Koichi UENO, \\ Takashi IGARASHI and Haruo KITAGAWA \\ Laboratory of Biochemical Pharmacology and Biotoxicology, \\ Faculty of Pharmaceutical Sciences, Chiba University, 1-33 Yayoi-cho, Chiba 260, Japan
}

Accepted May 9, 1984

\begin{abstract}
Addition of liver cytosol from $16 \mathrm{hr}$-starved rats treated with 6 -aminonicotinamide to rat liver microsomes caused potentiation of the anti-carboxylesterase action of ethyl-p-nitrophenyl phenylphosphonothioate (EPN). This was not found when liver cytosol from non-pretreated rats after $16 \mathrm{hr}$-starvation was used. This potentiation of EPN-induced inhibition of carboxylesterase may be, at least in part, explained by the fact that treatment of rats with 6 -aminonicotinamide resulted in a significant increase in NADPH level in liver cytosol which, in turn, stimulated formation of an EPN oxygen analog, a potent inhibitor of carboxylesterase, through cytochrome P-450-coupled monooxygenase.
\end{abstract}

Nonspecific carboxylesterase (EC. 3.1.1.1) in liver microsomes is well documented to be more susceptible to organophosphorus insecticides than acetylcholinesterase in vivo $(1-6)$. We have already reported that addition of NAD to the incubation mixture containing both liver microsomes and EPN caused remarkable potentiation of carboxylesterase inhibition by EPN (7). In this study, it is important that pyridine nucleotide contents in liver cytosol are closely related to the liver microsomal drug metabolism which is coupled with cytochrome P-450.

On the other hand, 6-aminonicotinamide (6-AN) has been known to alter the content of pyridine nucleotides in liver, which may affect the pyridine nucleotide-dependent enzyme activities in liver tissue (8-10). Our previous paper (11) demonstrated that cytochrome P-450 content and aminopyrine Ndemethylase activity in liver microsomes were increased by treatment of rats with 6-AN.

The present study was undertaken to investigate the changes in pyridine nucleotide contents in the liver cytosol of 6-AN-treated rats and the effect of the cytosol from 6-ANtreated rats on liver microsomal carboxyl- esterase activity in vitro.

\section{Materials and Methods}

Animals: Adult male rats of the Wistar strain, weighing 200-250 g, were used. They were maintained on standard laboratory chow (Oriental Yeast Co., MF) and tap water ad libitum under a condition of constant room temperature $\left(23-25^{\circ} \mathrm{C}\right)$ for at least one week before use.

Chemicals: EPN (analytical standard, $99+\%)$ was purchased from Wako Pure Chemicals, Inc, Tokyo, Japan. Prior to use in the experiments, EPN was subjected to thin layer chromatography to remove the contaminants such as $\mathrm{S}$-alkyl isomer and oxygen analog of EPN $(E P N=O)$, and it was purified by recrystallization from chloroform: methanol $(1: 1, v / v)$. No contamination of the recrystallized product could be detected by thin layer chromatography on a silica gel plate (Kieselgel 60 F254) using iodide as the detection reagent. The solvent system used to develop these thin layer plates was $n$ hexane:chloroform:methanol $(7: 3: 1, v / v)$. In this solvent system, EPN and $E P N=O$ have $\mathrm{Rf}$ values of 0.69 and 0.44 , respectively. An 
authentic sample of $E P N=O$ was prepared according to the method of $\mathrm{Neal}$ and DuBois (12) with minor modification by Satoh et al. (7).

Glucose 6-phosphate (G-6-P), G-6-P dehydrogenase (type $\mathrm{VI}$ ), NADP, NADH and NADPH were purchased from Oriental Yeast Co., Tokyo; 6-aminonicotinamide and $\beta$ $\mathrm{NAD}^{+}$(yeast, grade III) were from Sigma Chemical Co., St. Louis, MO; Isocarboxazid was kindly donated by Nippon Roche Co., Kamakura, Japan. All other chemicals were analytical or reagent grade.

Preparation of liver microsomes and cytosol: The rats were sacrificed by decapitation, their livers were perfused with $1.15 \%$ $\mathrm{KCl}$ to remove the blood and then homogenized in two volumes of $1.15 \% \mathrm{KCl}$. The $33 \%$ homogenate was centrifuged at $9,000 \times \mathrm{g}$ for $20 \mathrm{~min}$, and the supernatant obtained was recentrifuged at $105,000 \times \mathrm{g}$ for $60 \mathrm{~min}$ to sediment microsomes. The postmicrosomal supernatant was used as a cytosol fraction in this study. The microsomes were washed once with $1.15 \% \mathrm{KCl}$ and were used either the same day, or they were suspended in $1.15 \%$ $\mathrm{KCl}$ and stored at $-70^{\circ} \mathrm{C}$ under nitrogen gas until used.

Enzyme assay: Carboxylesterase activity was determined using the colorimetric assay procedure based on conversion of isocarboxazid to benzylhydrazine as described previously (6). Activities of $\mathrm{N}$-demethylase towards aminopyrine and ethylmorphine and activity of aniline hydroxylase were deter- mined in terms of the formaldehyde formation by the method of Nash (13) and in terms of the formation of $p$-aminophenol by the method of Imai et al. (14), respectively.

Determination of pyridine nucleotide content: NAD and NADP contents were determined spectrophotometrically by measuring the increase in absorbance at $340 \mathrm{~nm}$ in the presence of either alcohol dehydrogenase or G-6-P and G-6-P dehydrogenase, respectively (15). NADH and NADPH contents were determined according to the procedure described above after conversion to the respective oxidized form.

Determination of $E P N=0$ : $E P N=O$ formed in the incubation mixture after $10 \mathrm{~min}$ incubation was determined by the GC/MS method described in the previous paper (7).

Protein concentration was determined by the method of Lowry et al. (16).

All data in this study were statistically analyzed by Student's $t$-test.

\section{Results}

Enhancement of EPN-induced inhibition of microsomal carboxylesterase by liver cytosol in vitro: Inhibition of liver microsomal carboxylesterase by EPN $\left(1 \times 10^{-5} \mathrm{M}\right)$ was clearly potentiated by addition of liver cytosol from non-treated, fed rats (Table 1). In contrast, there was almost negligible enhancement of EPN-induced inhibition of carboxylesterase when cytosol from rats starved for $16 \mathrm{hr} \quad(17: 00-9: 00)$ prior to sacrifice was added to the liver microsomes

Table 1. Effects of rat liver cytosol on EPN-induced inhibition of liver microsomal carboxylesterase

\begin{tabular}{ccc}
\hline EPN & Cytosol added & Carboxylesterase activity \\
- & - & $63.7 \pm 3.5$ \\
+ & - & $56.6 \pm 3.5$ \\
- & non-treated, fed & $66.9 \pm 11.8$ \\
+ & non-treated, fed & $5.8 \pm 0.5^{*}$ \\
+ & non-treated, starved ${ }^{1)}$ & $62.0 \pm 3.5$ \\
+ & 6-AN-treated, starved & \\
\hline
\end{tabular}

Carboxylesterase activity is shown as nmoles benzylhydrazine formed/mg protein/30 min. 1) Rats were starved for $16 \mathrm{hr}$ prior to sacrifice, and cytosol was prepared. 2) 6-Aminonicotinamide (6-AN) was administered intraperitoneally to rats at a dose of $15 \mathrm{mg} / \mathrm{kg} 16 \mathrm{hr}$ before sacrifice. The incubation mixture consisting of 2-3 $\mathrm{mg}$ protein of the microsomal pellet, $1 \times 10^{-5} \mathrm{M}$ of EPN, $0.5 \mathrm{ml}$ of cytosol (protein approx. $10 \mathrm{mg}$ ) and $1 \mathrm{mM}$ of isocarboxazid as substrate in $0.2 \mathrm{M}$ Tris- $\mathrm{HCl}$ buffer $(\mathrm{pH} 8.0)$ was incubated at $37^{\circ} \mathrm{C}$ for $30 \mathrm{~min}$ following $10 \mathrm{~min}$-preincubation in the absence of isocarboxazid. Each value is the mean \pm S.E. from $7-8$ experiments. ${ }^{*} \mathrm{P}<0.01$ vs. the EPN alone group. 
from fed rat liver. These findings strongly suggested that diet-controlled component(s) in the cytosol may be involved in the potentiation, and pyridine nucleotides were considered as the compounds responsible for the potentiation.

On the other hand, 6-AN was injected intraperitoneally at a dose of $15 \mathrm{mg} / \mathrm{kg}, 16 \mathrm{hr}$ prior to sacrifice, and its effect on the EPNinduced inhibition of carboxylesterase was examined.

Table 1 also showed that addition of liver cytosol from starved rats treated with 6-AN caused remarkable potentiation of carboxylesterase inhibition by EPN in vitro, while no significant change in carboxylesterase inhibition by EPN was observed when 6-AN itself was added in the incubation mixture containing EPN and liver microsomes (data not shown).

Pyridine nucleotide contents in liver cytosol: Rats were treated with 6-AN (15 $\mathrm{mg} / \mathrm{kg}$, i.p.) and subjected to $16 \mathrm{hr}$ starvation. They were sacrificed $16 \mathrm{hr}$ later, and the liver cytosol was prepared as described in the Materials and Methods. As shown in Table 2, NADPH contents in liver cytosol was remarkably decreased by starvation (group 2.), while 6-AN treatment caused a 2 -fold increase in NADPH content and decrease in NAD content.

Changes in liver microsomal drug metabolizing enzyme activities by addition of liver cytosol: As shown in Table 3, a significant increase in aminopyrine $\mathrm{N}$ demethylase activity was observed when the liver cytosol from non-treated, fed rats was added to the incubation mixture containing liver microsomes without added NADPHgenerating system.

Determination of EPN $=0$ content formed by addition of liver cytosol from 6-ANtreated, starved rats: In order to clarify the potentiation of EPN-induced inhibition of carboxylesterase by the cytosol, the amount of $E P N=O$ formed was determined when liver cytosol from 6-AN-treated, starved rats were added to the incubation mixture con-

Table 2. Effects of 6-aminonicotinamide on pyridine nucleotide contents in rat liver cytosol

\begin{tabular}{lcccc}
\hline $\begin{array}{l}\text { Pre- } \\
\text { treatment }\end{array}$ & NAD & \multicolumn{3}{c}{$\begin{array}{c}\text { Pyridine nucleotide contents } \\
\text { (nmoles/ml of cytosol) }\end{array}$} \\
& NADP & NADH & NADPH \\
\hline None (fed) & $8.4 \pm 1.2$ & $7.1 \pm 1.1$ & $1.8 \pm 1.3$ & $22.4 \pm 2.7$ \\
None (starved) & $7.0 \pm 0.9$ & $4.8 \pm 0.5$ & $0.2 \pm 0.2$ & $4.2 \pm 0.6^{* *}$ \\
6-AN (starved) & $5.4 \pm 0.6^{*}$ & $5.7 \pm 1.1$ & $0.5 \pm 0.4$ & $9.0 \pm 1.6^{* * \ldots}$ \\
\hline
\end{tabular}

Rats were starved and concurrently administered 6-AN intraperitoneally at a dose of $15 \mathrm{mg} / \mathrm{kg} 16 \mathrm{hr}$ before sacrifice. Each value is the mean \pm S. E. from 7-10 animals. ${ }^{*} \mathrm{P}<0.05$ and ${ }^{*}{ }^{*} \mathrm{P}<0.01 \mathrm{vs}$. the nontreated, fed group. ${ }^{\sharp} P<0.05$ vs. the non-treated, starved group. For details, see the legend to Table 1.

Table 3. Drug metabolizing enzyme activities in the presence or absence of EPN, cytosol and NADPHgenerating system

\begin{tabular}{lccc}
\hline Addition & $\begin{array}{c}\text { Aminopyrine } \\
\text { N-demethylase }\end{array}$ & $\begin{array}{c}\text { Ethylmorphine } \\
\text {-demethylase }\end{array}$ & $\begin{array}{c}\text { Aniline } \\
\text { hydroxylase }\end{array}$ \\
None & $0.5 \pm 0.3$ & $0.6 \pm 0.3$ & $0.0 \pm 0.0$ \\
EPN alone & $0.4 \pm 0.2$ & $0.4 \pm 0.3$ & $0.0 \pm 0.0$ \\
EPN+Cytosol & $1.9 \pm 0.3^{*}$ & $1.1 \pm 1.0$ & $0.1 \pm 0.1$ \\
Complete system $^{3)}$ & $58.9 \pm 6.4^{* *}$ & $60.5 \pm 8.3^{* *}$ & $16.6 \pm 2.0^{* *}$ \\
\hline
\end{tabular}

Concentration of EPN added was $1 \times 10^{-5} \mathrm{M}$. Protein content of cytosol added was 3-5 mg per incubation mixture. 1) nmoles formaldehyde formed/mg protein $/ 30 \mathrm{~min}$. 2) nmoles $\mathrm{p}$-aminophenol formed $/ \mathrm{mg}$ protein/30 min. 3) Complete system consists of components usually used for assay of drug metabolizing enzyme activities, including the NADPH-generating system. Each value is the mean \pm S.E. from 3-5 experiments. ${ }^{*} \mathrm{P}<0.05$ and ${ }^{*} \mathrm{P}<0.01$ vs. the EPN alone group. 
Table 4. Effects of liver cytosol on the enzymatic formation of EPN=O from EPN added to fed or starved microsomes of rat liver in vitro

\begin{tabular}{|c|c|c|c|c|}
\hline Ms & EPN & Cytosol added & $\begin{array}{c}E P N=O \text { formed } \\
\left(\times 10^{-6} \mathrm{M}\right)\end{array}$ & $\%\left(\frac{E P N=O}{E P N \text { added }}\right)$ \\
\hline \multirow{5}{*}{ Fed } & + & - & N.D. & $<0.1$ \\
\hline & + & non-treated, fed & $2.80 \pm 0.55$ & 18.7 \\
\hline & + & non-treated, starved ${ }^{1)}$ & $0.64 \pm 0.40^{*}$ & 4.3 \\
\hline & + & $6-\mathrm{AN}$-treated, starved ${ }^{2)}$ & $1.99 \pm 0.88$ & 13.3 \\
\hline & + & 6-AN-treated, starved +SKF 525-A & N.D. & $<0.1$ \\
\hline \multirow{5}{*}{ Starved } & + & - & N.D. & $<0.1$ \\
\hline & + & non-treated, fed & $1.99 \pm 0.26$ & 13.3 \\
\hline & + & non-treated, straved ${ }^{1)}$ & $0.23 \pm 0.02^{* *}$ & 1.5 \\
\hline & + & $6-\mathrm{AN}$-treated, starved ${ }^{2)}$ & $0.83 \pm 0.26^{*}$ & 5.5 \\
\hline & + & 6-AN-treated, starved +SKF 525-A & N.D. & $<0.1$ \\
\hline
\end{tabular}

The initial concentration of EPN added here was $1.5 \times 10^{-5} \mathrm{M}$. The concentrations of cytosol and SKF 525-A used were 6-9 $\mathrm{mg}$ protein in $1 \mathrm{ml}$ of incubation mixture and $1 \mathrm{mM}$, respectively. 1) Rats were starved for $16 \mathrm{hr}$ prior to sacrifice, and cytosol was prepared. 2) 6 -Aminonicotinamide (6-AN) was administered intraperitoneally to rats at a dose of $15 \mathrm{mg} / \mathrm{kg} 16 \mathrm{hr}$ before sacrifice. Each value is the mean \pm S.E. from 3 experiments. N.D.: less than $0.13 \times 10^{-7} M .{ }^{*} P<0.05$ and ${ }^{*} P<0.01$ vs. the nontreated, fed-group.

taining liver microsomes and EPN without added NADPH-generating system.

As shown in Table 4, in vitro formation of $E P N=O$ from EPN was significantly decreased by addition of liver cytosol from starved rats, as compared to that from fed rats, to liver microsomes from fed rats. On the other hand, addition of cytosol from 6-AN treated and starved rats stimulated $\mathrm{EPN}=\mathrm{O}$ formation. These phenomena occurred to a lesser extent when liver microsomes of starved rats were used. In addition, in vitro inhibition of $E P N=O$ formation by SKF 525-A supported the well known finding that $\mathrm{EPN}=\mathrm{O}$ formation from EPN is catalyzed through cytochrome P-450-coupled drug metabolism in the liver.

\section{Discussion}

It has been well established that pure organophosphorothioates have virtually no activity against carboxylesterase and acetylcholinesterase in vitro; however, they become active in in vivo and in vitro studies by conversion to their respective oxygen analogs through the cytochrome P-450coupled monooxygenase system in the presence of NADPH.

The present study demonstrates that NADPH content in liver cytosol was increased by treatment of rats with $6-\mathrm{AN}$, and this seemed to be responsible for the potentiation of the inhibition of carboxylesterase by EPN. Thus, formation of $E P N=O$ was increased by addition of the cytosol from 6-AN-treated rat liver. In addition, aminopyrine $\mathrm{N}$-demethylase activity was also increased by addition of liver cytosol, instead of the NADPHgenerating system, from fed rats which contained a high level of NADPH. On the other hand, Johnson and McColl (17) and Dietrich et al. (18) have reported that 6-AN can replace the nicotinamide moiety of $\operatorname{NAD}(P)$, giving rise to the formation of an abnormal NAD molecule. Therefore, we are tentatively assuming that the increase in NADPH in liver cytosol was due to the effect of 6-ANAD $(P)$, but not 6-AN itself, formed in 6 -AN-treated rat liver, because there was no significant increase in the anti-carboxylesterase action of EPN when 6-AN was added in the incubation mixture in vitro (data not shown).

\section{References}

1 DuBois, K.P., Kinoshita, F.K. and Frawley, J.P.: Quantitative measurement of inhibition of aliesterases, acylamidase and cholinesterase by EPN and Delnav. Toxicol. Appl. Pharmacol. 12, 273-285 (1968)

2 Su, M.Q., Kinoshita, F.K., Frawley, J.P. and 
DuBois, K.P.: Comparative inhibition of aliesterases and cholinesterase in rats fed eighteen organophosphorus insecticides. Toxicol. Appl. Pharmacol. 20, 241-249 (1971)

3 Chen, T.S., Kinoshita, F.K. and DuBois, K.P.: Acute toxicity and antiesterase action of O-ethylS.S-diphenyl phosphorodithioate (Hinosan ${ }^{\circledR}$ ). Toxicol. Appl. Pharmacol. 23, 519-527 (1972)

4 Satoh, T.: A liver arylamidase extremely sensitive to organophosphorus compounds. Life Sci. 13, 1181-1188 (1973)

5 Satoh, T. and Moroi, K.: Comparative studies on the inhibition of liver amidase, aminopeptidase and serum cholinesterase by EPN. Toxicol. App!. Pharmaco!. 25, 553-559 (1973)

6 Satoh, T. and Moroi, K.: Comparison between procaine and isocarboxazid metabolism in vitro by a liver microsomal amidase-esterase. Biochem. Pharmacol. 24, 1517-1521 (1975)

7 Satoh, T., Sugiyama, S. and Kitagawa, H.: Potentiation of ethyl p-nitrophenyl phenylphosphonothioate (EPN)-induced inhibition of liver microsomal carboxylesterase by NAD in vitro in rats. Res. Commun. Chem. Pathol. Pharmacol. 26, 547-562 (1979)

8 Kolbe, H., Keller, K., Lange, K. and Herken, H.: Studies of carbohydrate metabolism in rat kidney after pharmacological blockade of the pentose phosphate pathway. Naunyn Schmiedebergs Arch. Pharmakol. 271, 93-102 (1971)

9 Herken, H.: Antimetabolic action of 6-aminonicotinamide on the pentose phosphate pathway in the brain. In Symposium on Mechanism of Toxicity, Edited by Aldridge, W.N., p. 189-203, McMillan and Co., Ltd., London (1971)

10 Bielicki, L. and Krieglstein, J.: Decreased GABA and glutamate concentration in rat brain after treatment with 6-aminonicotinamide. Naunyn Schmiedebergs Arch. Pharmakol. 294, 157-160 (1976)

11 Sugiyama, S., Satoh, T., Uzalp, B., Ueno, K., Igarashi, T. and Kitagawa, H.: Effect of a single administration of 6-aminonicotinamide on hepatic microsomal drug metabolism in rats. Arch. Int. Pharmacodyn. Ther. (1984) (in press)

12 Neal, R.A. and DuBois, K.P.: Studies of the mechanism of detoxification of cholinergic phosphorothioates. J. Pharmacol. Exp. Ther. 148, 185-192 (1965)

13 Nash, T.: Colorimetric estimation of formaldehyde by means of Hantzsch reaction. Biochem. J. 55, 416-421 (1953)

14 Imai, Y., Ito, A. and Sato, R.: Evidence for biologically different types of vesicles in the hepatic microsomal fraction. J. Biochem. 60 , 417-418 (1966)

15 Klingenberg, M.: Nicotinamide-adenine dinucleotides, spectrophotometric and fluorimetric methods. In Methods of Enzymatic Analysis, Edited by Bergmeyer, H.U., 2nd edition 4. p. 2045-2059. Academic Press, Inc., New York and London (1974)

16 Lowry, O.H., Rosebrough, N J., Farr, A.L. and Randall, R.J.: Protein measurement with the Folin reagent. J. Biol. Chem. 193, 265-275 (1951)

17 Johnson, W.J. and McColl, J.D.: Antimetabolite activity of 6-aminonicotinamide. Fed. Proc. 15, 284 (1956)

18 Dietrich, L.S., Friedland, J.M. and Kaplan, L.A.: Pyridine nucleotide metabolism: Mechanism of action of the niacin antagonist, 6-aminonicotinamide. J. Biol. Chem. 233, 964-968 (1958) 